\title{
Is Drinking with Parents Associated with High-Risk Drinking among Adolescents?
}

\author{
Hilde Pape Ingeborg Rossow Elisabet E. Storvoll \\ Norwegian Institute for Alcohol and Drug Research (SIRUS), PB 565 Sentrum, Oslo, Norway
}

\section{Key Words}

Adolescents · Drinking with parents - Underage heavy drinking $\cdot$ Alcohol-related parenting $\cdot$ General parenting style

\begin{abstract}
Background/Aims: What are the implications of drinking with parents (DWP) on adolescents' drinking behavior? We expanded the meagre body of research on this controversial issue by assessing the association between the frequency of DWP and adolescent high-risk drinking, taking a number of parental factors into account. Method: Data stemmed from a subsample of 14-17-year-old current drinkers $(n=7,616)$ who participated in a cross-sectional Norwegian school survey (response rate: $84 \%$ ). Results: One in four reported DWP during the past year. The higher the frequency of DWP, the higher was the prevalence of high-risk drinking. Parental drunkenness, permissive alcohol-related parenting, and indicators of suboptimal parenting more generally also correlated with DWP. After controlling for these confounders, only frequent DWP remained significantly associated with high-risk drinking. Conclusions: DWP was related to adolescent high-risk drinking, yet the association was in part attributable to parents' drinking and parenting style. The risk of involvement in high-risk drinking was about the same for adolescents reporting no DWP and infrequent DWP, while it was significantly elevated among those reporting frequent
\end{abstract}

\begin{tabular}{ll}
\hline KARGER 125/\% & $\begin{array}{l}\text { (2015 S. Karger AG, Basel } \\
1022-6877 / 15 / 0216-0291 \$ 39.50 / 0\end{array}$ \\
$\begin{array}{l}\text { E-Mail karger@karger.com } \\
\text { www.karger.com/ear }\end{array}$ & $\begin{array}{l}\text { This is an Open Access article licensed under the terms of the } \\
\text { Creative Commons Attribution-NonCommercial 3.0 Un- } \\
\text { ported license (CC BY-NC) (www.karger.com/OA-license), } \\
\text { applicable to the online version of the article only. Distribu- } \\
\text { tion permitted for non-commercial purposes only. }\end{array}$
\end{tabular}

DWP. This study thus demonstrated that the frequency of DWP matters and that parents who drink with their adolescent children differ from other parents in important ways.

(c) 2015 S. Karger AG, Basel

\section{Introduction}

There is a scene in the 2013 award-winning French movie Blue Is the Warmest Colour in which the main character, a mid-teen girl, drinks wine with her parents at an ordinary family dinner. This scene would be unthinkable if it depicted everyday family life in many other Western countries. For instance, the minimum legal drinking age is 21 in the United States, and quite a few states prohibit serving of alcohol to younger people in private homes - including serving one's own adolescent children [1]. The policy in Europe is generally far more liberal, but the health authorities in countries such as Norway and Sweden have warned against underage drinking in a familial context, claiming that youngsters who drink with their parents are at a risk of heavy drinking in unsupervised settings.

However, as we will soon discuss, the research literature addressing this issue is meagre and inconclusive, and the studies have important limitations. This study overcomes some of these limitations, and it examines whether, and if so how, the frequency of drinking with parents (DWP) is 
related to high-risk drinking among Norwegian adolescents. The age limit for purchasing alcohol is 18 years in Norway, but neither underage drinking nor parental serving of alcohol to minors is illegal. Alcohol is not embedded in everyday life in Norway, but the quantity consumed when drinking occurs tends to be relatively high - especially among young people $[2,3]$.

\section{The Zero-Tolerance and the Potential}

\section{Harm-Reduction Approaches to DWP}

The question of whether parents should, or should not, consume alcohol with their adolescent children is surrounded by controversy. Two contradictory views are held, and both may be supported theoretically $[4,5]$.

According to proponents of the zero-tolerance approach, parents demonstrate that they approve of underage drinking by consuming alcohol with their children which, in turn, increases the children's risk of heavy drinking. Indeed, there is ample evidence that parental provision of alcohol is related to heavier adolescent drinking [6], as are parental acceptance of underage drinking and permissive alcohol-related rules [7-9]. However, this research has not specifically focused on DWP, and we found no studies that directly supported the zero-tolerance approach to the issue. Moreover, this approach presumes that DWP at any frequency signifies parental approval of adolescent drinking in any context as well as intake of unlimited amounts of alcohol - which has not been empirically scrutinized.

Two longitudinal studies may still be noted. One of them found that DWP was associated with adolescent drinking at home, which, in turn, increased the risk of subsequent problem drinking [10]. However, the direct impact of DWP was not reported. The other study showed that late teen girls who were allowed to drink at family meals increased their drinking to a greater extent than those who were not allowed, yet the extent to which DWP occurred was not assessed [11]. Further, one may assume that girls whose DWP experiences were confined to a few exceptional celebration dinners did not necessarily report that they were 'allowed to drink at family meals' - which connotes a general parental permission to do so.

The zero-tolerance approach has been countered by scholars whose view is that DWP is likely to reduce adolescents' risk of heavy drinking [12, 13]. Green et al. [14] claimed that 'drinking at home with parents is [...] generally deemed to be a safe and secure environment in which to learn to drink in moderation', and DWP has thus been described as a harm-reduction approach to underage drinking [15-17]. This approach relies on principles derived from the social learning theory [18], presuming that adolescents learn to drink sensibly through parental modeling, and by learning by doing under the guidance of their parents. It also relies on implicit and untested assumptions that parents are modeling low-risk drinking, and that the proposed learning effect of DWP generalizes to unsupervised drinking outside the family sphere.

Some cross-sectional studies show that DWP at the most recent drinking event is inversely related to adolescent heavy drinking [19-22], which has been taken as evidence in support of the harm-reduction approach. However, these studies are likely to be biased in favor of demonstrating an apparently protective effect of DWP [23]. Thus, the quantity consumed is generally far lower when adolescents drink with their parents rather than with their peers $[19,20,24]$, and the probability of reporting DWP at the last drinking event is elevated among those who drink with their parents relatively often, but rarely in other contexts. Evidence in support of the harm-reduction approach from studies using other measures of DWP appears to be nonexistent.

\section{Limitations and Unresolved Issues}

Surprisingly few studies shed light on the zero-tolerance and the harm-reduction approaches to DWP, and high-quality research on the topic is conspicuous in its absence.

Among other things, previous research has failed to examine whether the frequency of DWP matters, yet the zero-tolerance approach presumes that no DWP and infrequent DWP are linked differently to adolescent heavy drinking. However, a qualitative study conducted in the United States found that parents who generally enforced strict rules against underage drinking occasionally allowed their adolescent offspring to drink at special events [25]. Thus, rare exceptions may occur, suggesting that infrequent DWP might differ from frequent DWP, but not necessarily from no DWP in terms of parental restrictiveness.

Moreover, the two main approaches to DWP both rely on assumptions of causality, but few potential confounders have been taken into account in previous research. In this study, we examine whether parental factors that are predictive of adolescent heavy drinking also correlate with the frequency of DWP. Whether parents who drink with their children differ from other parents in important ways is unknown, but a recent study of Swedish adolescents showed that parental serving of alcohol - which may involve DWP - correlated with permissive parental attitudes toward underage drinking and lower levels of parental control [26]. Focusing specifically on DWP, this study pursues this issue. 


\section{Aims}

This study adds to the meagre literature on the link between DWP and adolescent high-risk drinking, and sheds light on the zero-tolerance and harm-reduction approaches to the issue. Due to the paucity of previous research, we addressed the following questions without having formulated any a priori hypotheses: is adolescent high-risk drinking associated with both infrequent and frequent DWP, and if so, are these associations attributable to parents' drinking, other parental alcohol socialization factors, and general parenting style?

\section{Methods}

\section{Sample and Design}

In 2004-2006, the Norwegian Institute for Alcohol and Drug Research conducted annual cross-sectional school surveys in 16 municipalities, covering all regions of the country. The main initial purpose was to examine whether a governmentally funded prevention project had succeeded in reducing adolescent substance use and related harm. Nine municipalities had received funding to participate in the prevention project, while seven were included as controls. The latter were selected in order to match the intervention municipalities with respect to factors such as population size and degree of urbanization [27-29]. The evaluation study found no effects on adolescent drinking [28, 29], and the prevalence of DWP was also not affected by the prevention project [29].

We used data from the 2006 survey. There were 91 junior and senior high schools in the 16 municipalities, of which 82 took part in the survey. The response rate at the participating schools was $84 \%$. In some schools, whole classes of students did not participate (because of excursions, etc.) and the response rate reached $86 \%$ when they were excluded from the gross sample. The study was conducted in accordance with the national guidelines for research ethics in the social sciences and approved by the Norwegian Social Science Data Services. Design, procedures, and data collection strategies have been described in detail elsewhere [27-29].

Our analyses were confined to 14-17-year-olds. There were nearly 14,000 respondents in this age group, of whom $7 \%$ reported that neither of their parents had consumed alcohol in the past 12 months and 38\% had not consumed alcohol themselves. These respondents had ipso facto not experienced any episodes of DWP in the same period and were therefore excluded. Furthermore, $5 \%$ of the remaining sample was excluded due to missing data on DWP and/or involvement in high-risk drinking. The final study sample comprised 7,616 current drinkers whose mean age was 15.9 years (SD 1.02). A bare majority (54\%) were girls, and $92 \%$ reported that both parents were born in Norway or in another Nordic country.

\section{Measures}

Some of the variables in this study were adapted from previous research, while others - including the items used to assess DWP - were developed in relation to the evaluation study [27-29].

Adolescent High-Risk Drinking. We used two dichotomous measures of risky drinking behavior in the previous 12 months as outcomes. Frequent heavy episodic drinking was operationalized as drinking to the point of feeling clearly intoxicated [cf. 30] twice a month or more often, which was reported by $19.5 \%$. Further, data on alcohol-induced blackout ('been somewhere without remembering how you got there') and motor impairment ('been so drunk that you could not stand upright') were used to construct a dichotomous measure of recurrent episodes of severe drunkenness. The former item is included in the Rutgers Alcohol Problem Index [31]. Respondents who had experienced either of these symptoms for a total of $5+$ times $(10.1 \%)$ were classified as highrisk drinkers, while those who reported no or fewer such drunkenness episodes were not classified as such. The correlation between the two drinking outcomes was moderate $(\mathrm{r}=0.40, \mathrm{p}<$ 0.001).

Drinking with Parents (DWP). Recall cues are likely to increase the accuracy of respondents' reports [32], and we assessed the frequency of DWP during the past 12 months in two different contexts: (i) at home and (ii) somewhere else. There were six response options: no times, once, 2-4 times, 5-10 times, 11-20 times, and more than 20 times. The two items were used to construct a dichotomous variable $(0$ vs. $1+)$ as well as a graded measure with four frequency categories: no, one, $2-4$, and $5+$ episodes of DWP. Some respondents reported DWP once at home and 2-4 times somewhere else, or vice versa $(n=194)$, implying that their total frequency of such drinking episodes was 3, 4, or 5 times. However, it is more likely that they had experienced 3 or 4 rather than 5 DWP episodes, and we categorized them accordingly. A similar ambiguity applied for respondents who reported DWP 2-4 times at home and equally often somewhere else $(n=175)$. They were included in the $5+$ category.

Parental Alcohol Socialization Factors. Separate questions about exposure to maternal and paternal intoxication were asked, using a response scale ranging from 1 (never) to 5 (some times a week). As in previous research [33], we merged the two items without changing the scale. That is, for respondents who had seen one parent intoxicated more often than the other, priority was given to the one with the highest frequency. We also applied a dichotomous measure on frequent exposure (i.e. monthly or weekly) to parental intoxication. Further, the respondents were asked about the frequency of parental provision of alcohol for unsupervised drinking during the previous 12 months, applying these six response options: never (coded 0 ), once (1), 2-4 times (3), 5-10 times (7.5), 11-20 times (15.5), and more than 20 times (25). Moreover, alcohol-related rule setting was captured through questions about parental permission to drink at home with peers and to arrange unsupervised parties at home (adapted from Van Zundert et al. [34]). The items were added together, yielding a scale ranging from 0 (not allowed to do any of these things) to 2 (no restrictions). The respondents were also asked as to what extent the following statement agreed with their impression or experiences: 'My parents would accept my getting drunk once in a while'. The response options ranged from 1 (corresponds very poorly) to 4 (corresponds very well).

General Parenting Style. The respondents reported whether they were allowed to stay out late in the evening without telling their parents where they were, and whether they had any time limits for being out at night during the weekend. The items were added up to construct an indicator for unrestrictive parenting, with values ranging from 0 (not allowed to do any of these things) to 2 (no restrictions). The respondents also reported the extent to 
Table 1. Associations between the frequency of drinking with parents (DWP) and indicators of high-risk drinking

\begin{tabular}{|c|c|c|c|c|c|}
\hline \multirow[t]{2}{*}{ Freq. of DWP } & \multirow[t]{2}{*}{$\mathrm{n}(\%)$} & \multicolumn{2}{|c|}{ Frequent heavy episodic drinking } & \multicolumn{2}{|c|}{ Recurrent drunkenness } \\
\hline & & $\%$ & OR (99\% CI) & $\%$ & OR (99\% CI) \\
\hline No times & $5,494(73.6)$ & 15.5 & ref. & 7.1 & ref. \\
\hline Once & $829(11.1)$ & 20.0 & $1.36(1.06-1.73)$ & 10.0 & $1.47(1.06-2.03)$ \\
\hline $2-4$ times & $775(10.4)$ & 27.9 & $2.11(1.68-2.65)$ & 14.6 & $2.25(1.67-3.02)$ \\
\hline $5+$ times & $815(6.5)$ & 48.5 & $5.14(4.02-6.57)$ & 35.4 & $7.19(5.47-9.45)$ \\
\hline
\end{tabular}

Percentages and crude odds ratios (99\% CI).

which four statements about parental monitoring and knowledge (adapted from Wichstrøm [35]) agreed with their impressions or experiences, including statements such as 'My parents often ask me who I have been with and where I have been when I have been out' and 'My parents usually know where I am and what I do in my spare time'. The response scale ranged from 1 (corresponds very poorly) to 4 (corresponds very well). The four items were added up and averaged (Cronbach's $\alpha=0.75$ ). Another eight items were averaged to construct an index of perceived parent-child relationship quality (Cronbach's $\alpha=0.89$ ), with examples such as 'My parents often tell me or show me that they love me', 'My parents understand my problems and worries', 'I can talk with my parents about (almost) everything', and 'I love my parents'. Again, the response scale ranged from 1 (corresponds very poorly) to 4 (corresponds very well).

\section{Statistical Analyses}

First, we conducted simple logistic regression analyses to examine whether both infrequent and frequent DWP were associated with the two dichotomous measures on high-risk drinking. To find out whether the observed associations were attributable to parental alcohol socialization and general parenting style, we then examined whether these potential confounders, in addition to age and gender, were related to both DWP and the two outcomes. Variations in proportions were assessed using cross-tabulations with Pearson's $\chi^{2}$ test, while analyses of variance with F-tests were used to assess differences between means. Subsequently, we assessed the correlations (Pearson's $r$ ) between all the confounding factors. Finally, shared correlates of DWP and highrisk drinking were taken into account in multiple logistic regression analyses. Both drinking outcomes were modeled in a twostep manner, that is, demographic covariates were included in the first block, while parental factors were added to the equation in the second block. Due to the large sample size and the high number of comparisons undertaken, we chose $1 \%$ as the level for statistical significance.

The conventional use of no exposure (i.e. no DWP) as a reference group implies that the results of the logistic regression analyses are directly relevant in the context of the zero-tolerance approach to DWP. We also examined whether frequent and infrequent DWP were differently related to high-risk drinking, which is of potential interest in relation to the harm-reduction approach. More precisely, we tested differences between regression coefficients using the $\mathrm{t}$ test.

\section{Results}

The prevalence of DWP was $16 \%$ in the full sample of 14-17-year-olds and $26 \%$ in the study sample of current drinkers. All subsequent analyses were restricted to the latter group. Table 1 shows that the higher the frequency of DWP, the greater were the proportions reporting frequent heavy episodic drinking and recurrent episodes of severe drunkenness. Compared with respondents who had not consumed alcohol with their parents, those who had done so once, 2-4 times, or 5+ times had statistically significantly increased odds of high-risk drinking. Thus, the two drinking outcomes were associated with both infrequent and frequent DWP.

Table 2 shows that age and gender, as well as all the parental factors were associated with the frequency of DWP and with both drinking outcomes.

Age, being male, frequent exposure to parental intoxication, the frequency of parental provision of alcohol for unsupervised drinking, permissive alcohol-related rules, parental acceptance of getting drunk, and unrestrictive parenting more generally were positively related to the frequency of DWP and to high-risk drinking. In addition, parental monitoring and the perceived quality of the parent-child relationship were inversely related to both DWP and the two drinking outcomes.

Table 3 shows that the associations between the confounding factors were generally quite weak. The strongest correlation was observed for the link between the quality of the parent-child relationship and parental monitoring/knowledge $(r=0.46)$. No other correlation coefficients exceeded 0.40 .

Table 4 shows how the association between DWP and high-risk drinking was modified when the confounders were accounted for. Compared with respondents who had not consumed alcohol with their parents, those who had done so once, 2-4 times, and 5+ times had signifi- 
Table 2. Variations in demographics and parental characteristics by the frequency of drinking with parents, frequent heavy episodic drinking, and recurrent episodes of severe drunkenness

\begin{tabular}{|c|c|c|c|c|c|c|c|c|}
\hline & \multicolumn{4}{|c|}{ Frequency of drinking with parents } & \multicolumn{2}{|c|}{$\begin{array}{l}\text { Frequent heavy } \\
\text { episodic drinking }\end{array}$} & \multicolumn{2}{|c|}{$\begin{array}{l}\text { Recurrent } \\
\text { drunkenness }\end{array}$} \\
\hline & no times & once & $2-4$ & $5+$ & no & yes & no & yes \\
\hline Mean age (range: $14-17$ ) & $15.8(1.02)$ & $15.9(1.04)$ & $16.0(0.97)$ & $16.2(0.96)$ & $15.8(1.04)$ & $16.2(0.85)$ & $15.9(1.02)$ & $16.1(0.93)$ \\
\hline Boys, \% & 45.3 & 46.1 & 47.6 & 58.9 & 45.3 & 51.6 & 45.4 & 55.5 \\
\hline Frequent exposure to parental intoxication ${ }^{1}, \%$ & 6.8 & 9.9 & 12.2 & 23.2 & 6.8 & 16.9 & 7.4 & 20.9 \\
\hline Mean frequency of parental alcohol supply $(0-25)^{2}$ & $0.39(1.96)$ & $1.12(3.17)$ & $2.35(5.02)$ & $7.51(9.33)$ & $0.64(2.57)$ & $3.23(6.86)$ & $0.79(2.96)$ & $4.41(8.09)$ \\
\hline $\begin{array}{l}\text { Mean score for parental acceptance of } \\
\text { drunkenness }(1-4)^{2}\end{array}$ & $2.08(1.05)$ & $2.45(1.08)$ & $2.73(1.06)$ & $3.01(1.09)$ & $2.12(1.06)$ & $2.76(1.09)$ & $2.19(1.07)$ & $2.75(1.15)$ \\
\hline $\begin{array}{l}\text { Mean score for permissive alcohol-related } \\
\text { rules }(0-2)^{2}\end{array}$ & $0.32(0.60)$ & $0.53(0.72)$ & $0.68(0.79)$ & $1.06(0.85)$ & $0.36(0.62)$ & $0.73(0.82)$ & $0.39(0.66)$ & $0.77(0.83)$ \\
\hline Mean score for unrestrictive parenting $(0-2)^{2}$ & $0.72(0.77)$ & $0.87(0.79)$ & $0.94(0.80)$ & $1.12(0.81)$ & $0.72(0.76)$ & $1.05(0.83)$ & $0.75(0.77)$ & $1.10(0.84)$ \\
\hline Mean score for parental monitoring $(1-4)^{2}$ & $3.44(0.57)$ & $3.35(0.62)$ & $3.33(0.64)$ & $3.13(0.84)$ & $3.44(0.57)$ & $3.23(0.74)$ & $3.43(0.57)$ & $3.07(0.82)$ \\
\hline $\begin{array}{l}\text { Mean score for parent-child relationship } \\
\quad \text { quality }(1-4)^{2}\end{array}$ & $3.18(0.61)$ & $3.16(0.60)$ & $3.17(0.61)$ & $3.05(0.81)$ & $3.20(0.59)$ & $3.03(0.73)$ & $3.20(0.60)$ & $2.89(0.78)$ \\
\hline Lowest, $\mathrm{n}$ & 5,449 & 812 & 760 & 497 & 6,053 & 1,446 & 6,743 & 754 \\
\hline
\end{tabular}

Means (SD) and percentages. Variations in percentages were assessed using cross-tabulations with Pearson's $\chi^{2}$ test and analyses of variance with F-tests were used to assess differences between means. All associations were statistically significant ( $\mathrm{p}<0.001$ or lower).

${ }^{1}$ Monthly or more often; ${ }^{2}$ scale range.

Table 3. Correlations between factors that confound the association between DWP and high-risk drinking

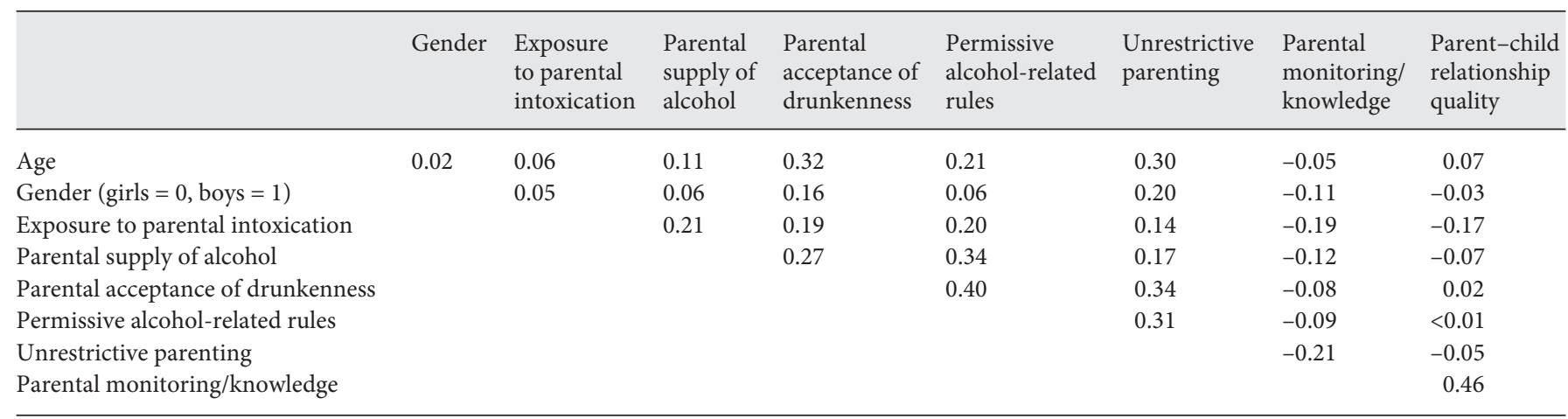

All correlation coefficients (Pearson's $r$ ) above 0.05 and below -0.05 are statistically significant ( $p<0.01$ or lower).

cantly elevated odds of reporting frequent heavy episodic drinking and recurrent episodes of severe drunkenness - irrespective of their age and gender (block 1). These associations are only slightly lower than those observed when no confounders were taken into account (see table 1). However, when we added parental factors to the equation (block 2), the associations declined markedly. Only frequent DWP (5+ times) was still statistically significant, while infrequent DWP was not. Moreover, we compared the results for infrequent DWP (2-4 times) and frequent DWP and found that the latter group had significantly higher odds of reporting fre- quent heavy episodic drinking $(\mathrm{t}=2.27, \mathrm{p}<0.05)$ and recurrent episodes of severe drunkenness $(\mathrm{t}=3.73$, $\mathrm{p}<$ 0.001 ). It may also be noted that almost all the other study variables were independently associated with both drinking outcomes.

\section{Discussion}

Although the potential implications of DWP on adolescents' risk of heavy drinking have been subject to much debate, very few studies have focused specifically on the 
Table 4. Odds ratios ( $99 \%$ CI) for the associations between the frequency of drinking with parents (DWP) and high-risk drinking, adjusting for age, gender (block 1), parental alcohol socialization factors, and indicators for general parenting (block 2)

Frequent heavy Recurrent episodic drinking drunkenness

\section{Block 1}

Frequency of DWP (ref: no times)

$\begin{array}{lll}\text { Once } & \mathbf{1 . 3 2}(1.02-1.70) & \mathbf{1 . 4 5}(1.03-2.02) \\ 2-4 \text { times } & \mathbf{1 . 9 5}(1.54-2.47) & \mathbf{2 . 1 5}(1.59-2.92) \\ 5+\text { times } & \mathbf{4 . 4 8}(3.46-5.82) & \mathbf{6 . 9 9}(5.26-9.27)\end{array}$

\section{Block 2}

Frequency of DWP

Once

2-4 times

$0.97(0.75-1.28)$

$1.21(0.93-1.57)$

$5+$ times

$1.73(1.27-2.37)$

$1.40(1.27-1.54)$

Age

$0.98(0.83-1.17)$

Gender (ref: female)

never)

Exp. to parental
A few times

$1.33(1.08-1.64)$

$1.80(1.38-2.34)$

Some times a year

Some times a month

Some times a week

$2.42(1.73-3.38)$

$2.17(1.36-3.45)$

$1.06(1.04-1.08)$

$1.12(0.78-1.58)$

$1.38(0.99-1.93)$

$2.79(1.96-3.97)$

$1.40(1.27-1.54)$

$0.98(0.83-1.17)$

$1.26(0.94-1.68)$

$1.60(1.13-2.26)$

$1.73(1.12-2.65)$

$3.02(1.80-5.09)$

Parental supply of alcohol

Parental acceptance of drunkenness

$1.28(1.17-1.40) \quad \mathbf{1 . 2 1}(1.07-1.35)$

Permissive alcohol-related rules

$1.25(1.10-1.41)$

$1.10(0.93-1.29)$

Unrestrictive parenting

Parental monitoring/ knowledge

$1.11(0.99-1.24) \quad 1.15(0.99-1.34)$

$\mathbf{0 . 8 1}(0.70-0.94) \quad \mathbf{0 . 6 9}(0.58-0.83)$

Parent-child relationship quality

$\mathbf{0 . 7 5}(0.64-0.86) \quad \mathbf{0 . 6 4}(0.53-0.77)$

Statistically significant $(\mathrm{p}<0.01$ or lower) odds ratios appear in bold type.

issue. Our study of underage drinkers in Norway expanded the meagre research literature by assessing how the frequency of DWP was associated with two different indicators for high-risk drinking, taking parental factors into account.

Bivariate analyses showed that the prevalence of risky drinking behavior increased markedly with the frequency of DWP. However, infrequent DWP was no longer significantly associated with high-risk drinking when parental alcohol socialization factors and indicators for general parenting style were accounted for. Previous research has applied dichotomous measures of DWP, and our study is the first to demonstrate that the frequency of such drinking episodes matters. It also provides new insights by assessing a range of parental correlates of DWP.
We found that frequent exposure to parental intoxication, frequent provision of alcohol for unsupervised drinking, permissive alcohol-related attitudes and rules, and unrestrictive parenting more generally correlated with DWP, as did lower levels of monitoring and lower parent-child relationship quality. In Norway, DWP thus seems to be embedded in a pattern of suboptimal parenting, which was particularly conspicuous in the group reporting frequent DWP. A previous study of Norwegian adolescents found a similar pattern, yet it relied on a global measure for the frequency of parental provision of alcohol [36]. Our findings also concur with those reported by Strandberg et al. [26], who found that permissive parental attitudes toward underage drinking and weak parental control predicted parental serving of alcohol.

All the parental factors that we gauged were also significantly related to risky drinking behavior, which agrees with previous research [6-9]. When we adjusted for these factors, adolescents reporting no DWP and those reporting infrequent DWP were approximately equally likely to report frequent heavy episodic drinking and recurrent episodes of severe drunkenness. Hence, our results did not support the zero-tolerance approach to the issue. The inclusion of parental factors in regression models also implied that the statistical impact of frequent DWP on both drinking outcomes was attenuated, yet it remained statistically significant. This finding calls for an explanation.

Considering that we assessed ordinary high school students and that the quantity of alcohol consumed with parents is typically low $[19,20,24]$, it is unlikely that frequent DWP correlated with high-risk drinking because these drinking episodes often involved adolescent drunkenness. It is possible, however, that our measure of parental intoxication, as well as some of the other parental factors that we assessed, was too crude to capture nuances of importance. The persistent statistical effect of frequent DWP on adolescent high-risk drinking may also reflect influences of a different nature than those captured in our study.

A conspicuously high proportion of the respondents who reported frequent DWP were exposed regularly to parental intoxication, and the parents' actual frequency of getting drunk was probably higher than that observed by their adolescent children. In some cases, this may indicate severe parental alcohol problems. There is ample evidence that children whose parents drink excessively are at risk of problem drinking themselves, which, in part, may reflect genetic susceptibility [37, 38]. Moreover, parental alcohol problems often co-occur with other risk factors for adolescent heavy drinking, such as family dys- 
function, maltreatment and neglect, and other adverse childhood experiences $[39,40]$. There is also evidence that the more the parents drink, the greater is the availability of alcohol at home [41, 42], which has been identified as another risk factor for adolescent heavy drinking [43].

Our results further pertain to the question of whether infrequent and frequent DWP may be qualitatively different, as the study by Friese et al. [25] seems to suggest. In families where DWP is a rarity, one may assume that such drinking events typically occur on special occasions where the parents, as an exception, allow their offspring to drink in moderation. Frequent DWP, on the other hand, may, to a greater extent, include less-regulated and less-responsible drinking practices. If so, parents of those who reported infrequent DWP are the ones who are most likely to follow the recommendations by advocates of the harm-reduction approach - whether this is intended or not. According to Epstein [44], the key question is whether adolescents who drink sensibly with their parents in appropriately supervised settings are less likely to adopt a risky drinking pattern. Admittedly, we did not assess whether DWP occurred in such settings, but infrequent DWP was not associated with less high-risk drinking. Hence, our results did not lend support to the harm-reduction approach to the issue.

\section{The Cultural Context}

A recent study of adolescents in 25 European countries showed that the proportion reporting DWP at the last drinking event varied from less than 15\% (Norway, Iceland, Estonia) to about 40\% (Italy, Cyprus) [24]. Within Europe, there are also significant cross-national variations in per capita consumption of alcohol, the drinking pattern, the use of alcohol by youth $[2,3]$, and the extent to which drunkenness is considered deviant [45]. The norms that regulate alcohol-specific parenting probably also show substantial variation.

In societies where DWP is prevalent and alcohol is integrated into ordinary family life, it seems likely that parents who drink with their adolescent children are unremarkable with respect to other parenting practices. In such societies, one may hypothesize that the association between DWP and adolescent high-risk drinking differs from that observed in our Norwegian study.

\section{Methodological Considerations and Avenues for \\ Future Research}

While previous research has relied on dichotomous measures of DWP, we assessed the frequency of such drinking episodes and could, consequently, examine potential differences between no DWP and infrequent DWP - which is particularly interesting in relation to the zero-tolerance approach. Furthermore, the data set stemmed from a large general population survey with a high response rate, and allowed us to adjust for a range of parental factors.

However, our cross-sectional design implies that the temporal order of DWP and high-risk drinking remains unknown, and that the potential causal mechanisms underlying the observed associations could not be pursued. Evidence that parenting practices and the parent-child relationship may be adversely affected if adolescents drink heavily [46-48] is relevant in this respect. Bidirectional associations between parental and adolescent drinking have also been found, implying that parents may increase their drinking when their children start using alcohol [49]. One can also not disregard the possibility that associations between DWP and heavier adolescent drinking may reflect bidirectional influences. To assess this complexity in relation to the topic at issue, longitudinal data are required.

Other important issues could also not be pursued. For instance, the situational context of DWP, the quantity imbibed at these drinking events, and the parents' motives for consuming alcohol with their underage offspring were not assessed. Obviously, additional research, including qualitative studies, is needed to reveal the stories behind our results. Another suggestion for future research is to examine the potential implications of DWP on adolescent drinking behavior in a cross-cultural context.

Furthermore, this study collected data on DWP by asking only the adolescents. However, parents may be reluctant to honestly answer questions about alcohol-related parenting practices $[25,50]$. Moreover, compared with adolescents' reports, parents typically report less approval of underage drinking, stricter alcohol-related rules, and higher levels of monitoring $[11,51]$. There is also evidence that parenting practices predict adolescent drinking behavior better when they are reported by the adolescents rather than by their parents [52-54].

\section{Conclusions}

We found that DWP was embedded in a pattern of suboptimal parenting and that frequent DWP was independently related to adolescent high-risk drinking. Moreover, adolescents with no DWP experiences and those 
who reported few such drinking episodes were about equally likely to engage in risky drinking behavior. Hence, the zero-tolerance approach to DWP was not supported. The results did not also support the view that adolescents may learn to drink sensibly by consuming alcohol with their parents. The paucity of studies on the issue, as well as the present research findings, suggests that both the zero-tolerance and the harm-reduction approaches to DWP should be rejected. None of them rely on empirical evidence, and both fail to take the complexity of the issue into account.

DWP is fairly uncommon in Norway, and our results cannot readily be generalized to other countries and drinking cultures. Limitations due to our cross-sectional study design should also be kept in mind. The potential causal mechanisms underlying the observed associations remain unknown, and additional research is required to make evidence-based recommendations for policy and prevention. However, our results may be taken as an indication that infrequent DWP does not per se increase the risk of adolescent heavy drinking, and that other parental practices may be more important to target.

\section{Acknowledgments}

The authors wish to thank Jasmina Burdzovic Andreas, $\mathrm{PhD}$, at the Norwegian Institute for Alcohol and Drug Research (SIRUS) and the anonymous reviewers for feedback that served to strengthen the quality of this article.

\section{Disclosure Statement}

The authors have no conflicts of interest to disclose.

\section{References}

1 Alcohol Policy Information System: Underage Drinking: Possession/Consumption/Internal Possession of Alcohol. NIAAA, 2013. http:// alcoholpolicy.niaaa.nih.gov/Home.html.

2 Bye EK, Rossow I: The impact of drinking pattern on alcohol-related violence among adolescents: an international comparative analysis. Drug Alcohol Rev 2010;29:131-137.

3 Babor T, Caetano R, Casswell S, Edwards G, Giesbrecht N, Graham K, Grube J, Gruenewald P, Hill L, Holder H, Homel R, Livingston M, Osterberg E, Rehm J, Room R, Rossow I: Alcohol: No Ordinary Commodity. Alcohol and Public Policy Group, ed 2. Oxford, Oxford University Press, 2010.

4 Roberts R, Beckwith M, Watts D: Mothers' intentions to introduce their adolescent to alcohol use: does mothers' alcohol use effect intentions? Aust N Z J Public Health 2010;34: 281-287.

5 Varvil-Weld L, Crowley DM, Turrisi R, Greenberg MT, Mallett KA: Hurting, helping, or neutral? The effects of parental permissiveness toward adolescent drinking on college student alcohol use and problems. Prev Sci 2014; 15:716-724.

6 Kaynak Ö, Winters KC, Cacciola J, Kirby KC, Arria AM: Providing alcohol for underage youth: what messages should we be sending parents? J Stud Alcohol Drugs 2014;75:590605.

7 Ryan SM, Jorm AF, Lubman DI: Parenting factors associated with reduced adolescent alcohol use: a systematic review of longitudinal studies. Aust N Z J Psychiatry 2010;44:774-783.

8 van der Vorst H: The role of parents in adolescent alcohol use; in Verster JC, Brady K, Galanter M, Conrod P (eds): Drug Abuse and Addiction in Mental Illness: Causes, Conse- quences and Treatment. New York, Springer, 2012, pp 497-503.

9 Ward B, Snow P: Supporting parents to reduce the misuse of alcohol by young people. Drug Educ Prev Policy 2010;17:718-731.

10 van der Vorst H, Engels RC, Burk WJ: Do parents and best friends influence the normative increase in adolescents' alcohol use at home and outside the home? J Stud Alcohol Drugs 2010;71:105-114.

11 Livingston JA, Testa M, Hoffman JH, Windle M: Can parents prevent heavy episodic drinking by allowing teens to drink at home? Addict Behav 2010;35:1105-1112.

12 Foxcroft DR, Lowe G: Adolescents' alcohol use and misuse: the socializing influence of perceived family life. Drug Educ Prev Policy 1997;4:215-229.

13 Peele S: Addiction-Proof Your Child: A Realistic Approach to Preventing Drug, Alcohol, and Other Dependencies. New York, Random House/Three Rivers Press, 2007.

14 Green G, Macintyre S, West P, Ecob R: Like parent like child? Associations between drinking and smoking behaviour of parents and their children. Br J Addict 1991;86:745-758.

15 Abar CC, Morgan NR, Small ML, Maggs JL: Investigating associations between perceived parental alcohol-related messages and college student drinking. J Stud Alcohol Drugs 2012; 73:71-79.

16 McMorris BJ, Catalano RF, Kim MJ, Toumbourou JW, Hemphill SA: Influence of family factors and supervised alcohol use on adolescent alcohol use and harms: similarities between youth in different alcohol policy contexts. J Stud Alcohol Drugs 2011;72:418-428.

17 Peele S: Reducing harms from youth drinking. J Alcohol Drug Educ 2006;50:67-87.
18 Bandura A: Social Learning Theory. Englewood Cliffs, NJ, Prentice-Hall, 1977.

19 Foley KL, Altman D, DuRant RH, Wolfson M: Adults' approval and adolescents' alcohol use. J Adolesc Health 2004;35:345.e17-e26.

20 Mayer RR, Forster JL, Murray DM, Wagenaar AC: Social settings and situations of underage drinking. J Stud Alcohol 1998;59:207-215.

21 Reboussin BA, Song EY, Wolfson M: Social influences on the clustering of underage risky drinking and its consequences in communities. J Stud Alcohol Drugs 2012;73:890-898.

22 Song EY, Smiler AP, Wagoner KG, Wolfson M: Everyone says it's ok: adolescents' perceptions of peer, parent, and community alcohol norms, alcohol consumption, and alcohol-related consequences. Subst Use Misuse 2012; 47:86-98.

23 Blanchette J, Heeren T: Methodology may exaggerate a beneficial effect of drinking with parents. J Stud Alcohol Drugs 2013;74:353.

24 Kask K, Markina A: With whom did you drink last time? An analysis of adolescents' alcohol use. Annu Res Rev Biol 2014;4:174187.

25 Friese B, Grube JW, Moore RS, Jennings VK: Parents' rules about underage drinking: a qualitative study of why parents let teens drink. J Drug Educ 2012;42:379-391.

26 Strandberg AK, Bodin MC, Romelsjö A: Gender differences in the prediction of parental servings of alcohol to adolescents and youth drunkenness. Subst Use Misuse 2014;49: 1857-1866.

27 Pape H, Rossow I, Storvoll EE: Report of the Study Methodology for the School Surveys 2004, 2005 and 2006 for Evaluation of the Regional Project. Oslo, Norwegian Institute for Alcohol and Drug Research, 2007. 
28 Rossow I, Storvoll EE, Baklien B, Pape H: Effect and process evaluation of a Norwegian community prevention project targeting alcohol use and related harm. Contemp Drug Probl 2011;38:441-466.

29 Baklien B, Pape H, Rossow I, Storvoll EE: Regionprosjektet - nyttig forebygging. Evalueringen av et pilotprosjekt om lokalbasert rusforebygging. SIRUS rapport $\mathrm{nr}$ 6/2007 [The regional project - useful prevention? Evaluation of a pilot project on community based alcohol and drug prevention SIRUS report no. 6/2007]. Oslo, Norwegian Institute for Alcohol and Drug Research, 2007.

30 Strand NP, von Soest T: Young in Norway Longitudinal. Documentation of Design, Variables and Scales. Oslo, Norwegian Social Research, 2007.

31 White HR, Labouvie EW: Towards the assessment of adolescent problem drinking. J Stud Alcohol 1989;50:30-37.

32 Schwarz N, Oyserman D: Asking questions about behavior: cognition, communication, and questionnaire construction. Am J Eval 2001;22:127-160.

33 Latendresse SJ, Rose RJ, Viken RJ, Pulkkinen L, Kaprio J, Dick DM: Parenting mechanisms in links between parents' and adolescents' alcohol use behaviors. Alcohol Clin Exp Res 2008;32:322-330.

34 Van Zundert RM, Van Der Vorst H, Vermulst AA, Engels RC: Pathways to alcohol use among Dutch students in regular education and education for adolescents with behavioral problems: the role of parental alcohol use, general parenting practices, and alcohol-specific parenting practices. J Fam Psychol 2006; 20:456-467.

35 Wichstrøm L: Psychological and behavioral factors unpredictive of disordered eating: a prospective study of the general adolescent population in Norway. Int J Eat Disord 2000; 28:33-42.

36 Pape H, Storvoll EE: 'Foreldrelanging' og ungdomsfyll [Parental alcohol 'pushing' and adolescent drunkenness]. Tidsskrift for Ungdomsforskning 2005;5:51-70.

37 Agrawal A, Lynskey MT: Are there genetic influences on addiction: evidence from family, adoption and twin studies. Addiction 2008; 103:1069-1081.

38 Tyndale RF: Genetics of alcohol and tobacco use in humans. Ann Med 2003;35:94-121.

39 Dube SR, Anda RF, Felitti VJ, Croft JB, Edwards VJ, Giles WH: Growing up with parental alcohol abuse: exposure to childhood abuse, neglect, and household dysfunction. Child Abuse Negl 2001;25:1627-1640.

40 Jennison KM: The impact of parental alcohol misuse and family environment on young people's alcohol use and behavioral problems in secondary schools. J Subst Use 2014;19:206-212.

41 Komro KA, Maldonado-Molina MM, Tobler AL, Bonds JR, Muller KE: Effects of home access and availability of alcohol on young adolescents' alcohol use. Addiction 2007;102: 1597-1608.

42 Maddahian E, Newcomb MD, Bentler PM: Adolescents' substance use: impact of ethnicity, income, and availability. Adv Alcohol Subst Abuse 1986;5:63-78.

43 van den Eijnden R, Mheen DV, Vet R, Vermulst A: Alcohol-specific parenting and adolescents' alcohol-related problems: the interacting role of alcohol availability at home and parental rules. J Stud Alcohol Drugs 2011;72: 408-417.

44 Epstein DH: A comment on van der Vorst et al. (2010). J Stud Alcohol Drugs 2010;71:615616; author reply 616-618.

45 Nordlund S, Østhus S: What is alcohol abuse? Attitudes to drinking in seven European coun- tries. Addict Res Theory 2013;21:402-409.

46 Coley RL, Votruba-Drzal E, Schindler HS: Trajectories of parenting processes and adolescent substance use: reciprocal effects. J Abnorm Child Psychol 2008;36:613-625.

47 Huh D, Tristan J, Wade E, Stice E: Does problem behavior elicit poor parenting? A prospective study of adolescent girls. J Adolesc Res 2006;21:185-204.

48 Stice E, Barrera M: A longitudinal examination of the reciprocal relations between perceived parenting and adolescents' substance use and externalizing behaviors. Dev Psychol 1995;31:322-334.

49 Otten R, van der Zwaluw CS, van der Vorst $\mathrm{H}$, Engels RC: Partner effects and bidirectional parent-child effects in family alcohol use. Eur Addict Res 2008;14:106-112.

50 Kypri K, Dean JI, Stojanovski E: Parent attitudes on the supply of alcohol to minors. Drug Alcohol Rev 2007;26:41-47.

51 Varvil-Weld L, Turrisi R, Scaglione N, Mallett KA, Ray AE: Parents' and students' reports of parenting: which are more reliably associated with college student drinking? Addict Behav 2013;38:1699-1703.

52 Latendresse SJ, Rose RJ, Viken RJ, Pulkkinen L, Kaprio J, Dick DM: Parental socialization and adolescents' alcohol use behaviors: predictive disparities in parents' versus adolescents' perceptions of the parenting environment. J Clin Child Adolesc Psychol 2009;38: 232-244.

53 Cohen DA, Rice J: Parenting styles, adolescent substance use, and academic achievement. J Drug Educ 1997;27:199-211.

54 Cottrell L, Li X, Harris C, D’Alessandri D, Atkins M, Richardson B, et al: Parent and adolescent perceptions of parental monitoring and adolescent risk involvement. Parent Sci Pract 2003;3:179-195. 